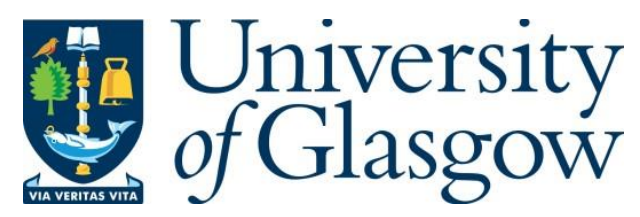

Fotouhi, M., Saghafi, H., Brugo, T., Minak, G., Fragassa, C., Zucchelli, A. and Ahmadi, M. (2017) Effect of PVDF nanofibers on the fracture behavior of composite laminates for high-speed woodworking machines. Proceedings of the Institution of Mechanical Engineers Part C: Journal of Mechanical Engineering Science, 231(1), pp. 31-43.

There may be differences between this version and the published version. You are advised to consult the publisher's version if you wish to cite from it.

http://eprints.gla.ac.uk/197501/

Deposited on: 26 September 2019

Enlighten - Research publications by members of the University of Glasgow http://eprints.gla.ac.uk 


\title{
Effect of PVDF nanofibers on the fracture behaviour of composite laminates for high speed woodworking machines
}

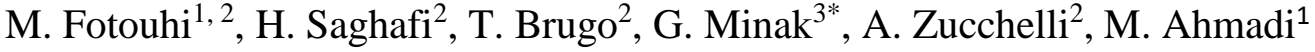 \\ 1-Non-destructive Testing Lab., Department of Mechanical Engineering, Amirkabir University of Technology, 424 Hafez Ave., 15914, Tehran, Iran \\ 2- Department of Industrial Engineering (DIN), University of Bologna, Viale del Risorgimento 2, 40136 Bologna, Italy \\ 3- Department of Industrial Engineering (DIN), University of Bologna, via Fontanelle 40, 47121 Forlì, Italy. \\ * Corresponding Author: giangiacomo.minak@unibo.it
}

\begin{abstract}
The use of light composites when designing fast moving parts for machine tools is emerging as a very efficient solution for improving productivity. Nevertheless several aspects of these materials have to be carefully considered in woodworking. This paper aims to investigate the effect of interleaved nanofiber on mode I interlaminar properties and the failure modes that occur in this mode. For this purpose, woven carbon/epoxy laminates with and without Polyvinylidene difluoride nanofibers in the mid-plane were subjected to mode I interlaminar loading and the results were compared with each other. Acoustic Emission technique was also utilized for better understanding of the failure modes that occurred in the virgin and nanofibersmodified specimens. Mechanical data and acoustic emission parameters associated with pattern recognition analyses were used for investigation of the interlaminar properties and the occurred failure modes. The mechanical results showed that the electrospun nanofibrous mat was able to increase the GIC by $98 \%$. The AE results highlighted that different failure modes were the origin of different interlaminar failure behaviors. Different percentages of the failure modes in the
\end{abstract}


modified specimens compared with the virgin ones were observed. Furthermore, the number of occurred interlaminar failure modes diminished in the modified composite layers.

Key words: Carbon/epoxy laminates, PVDF Nano-fibres, Delamination, Acoustic emission.

\section{Introduction}

High performance fiber reinforced polymer composites are lighter and have higher specific stiffness and strength compared with metallic materials. As a result, they are increasingly used in applications where a low mass can reduce inertia forces, like high speed woodworking machines. The relevance of high speeds in machining for improving the productivity of processes and competitiveness of products in the specific case of woodworking, together with an overview of several technical solutions recently used in the design of machine tools, including an investigation on the effect of changes in materials, are presented in [1].

Considering their specific morphology, composites laminates are resistant to in-plane stresses, but weak in out-of-plane stresses, like the ones arising from impacts of wood projectiles during woodworking, which leads to one of their most insidious failure modes: delamination [2]. In woodworking, fast projectiles escaping from the working area do not represent rare phenomena: they usually consist in wooden chips but, sometimes, even heavy metal slivers are involved, as in the case of parts of broken tools (e.g. blades) [3].

In order to prevent delamination, different methods were developed and evaluated in the past few decades, such as stitching of the laminas, matrix-toughening and three-dimensional braided fabrics [3-7]. Among these techniques, matrix-toughening is one of the most suitable methods, where an 
increase in delamination toughness may result by inserting interleaf layers of toughened materials between the layers on the fabrication process of the laminate [8-10].

Dzenis and Reneker [11] proposed to interleave a laminate with polymeric nanofibrous non-woven mats produced by electrospinning process. Compared to microfibers, nanofibers have a higher surface-area-to-volume ratio, higher porosity and better ability to conform to the shape of the primary reinforcing fibers at the ply interface. The presence of the nanofibers at the interlayer is expected to reduce stress concentration at the plies interface, caused by the mismatch of plies properties, and to bond the adjacent plies. Furthermore, due to its dimensions, the nanofiber mat does not reduce the original in-plane mechanical performance and does not increase the weight and the thickness of the laminate [12].

Up to now various kinds of polymeric nanofibers have been introduced by researchers for improving fracture toughness of composite laminates: Nylon 6 [13], Nylon 6,6 [14-18], Phenoxy [19], polyvinylidene difluoride (PVDF) [20-22], Polysulfone (PSF) [23], Polycaprolactone (PCL) [24-25]. Except PVDF, most other nanofibers have been investigated from different points of view. For example, the effect of Nylon 6,6 nanofibers on mechanical behavior of carbon or glass/epoxy laminates has been considered using different mechanical tests such as mode I and mode II fracture tests [16-17], drop-weight impact test [12, 15], fatigue test [26], damping test [26], etc. In addition, some techniques and equipment like Scanning Electron Microscope (SEM) and Acoustic emission (AE) were also applied to find out the mechanism of toughening and failure modes for the investigated specimens $[16,20]$.

PVDF nanofibers were not considered suitable for increasing mode I fracture toughness of epoxybased laminates [21-22], but recently it was found that there is a possibility in a specific situation 
such as appropriate curing temperature and nanofibrous mat thickness [20]. For this reason, there is very limited information regarding the toughening and failure mechanisms of PVDF-interleaved laminates. This paper is aiming to investigate these mechanisms using $\mathrm{AE}$ technique. AE signal is a spontaneous transient energy released by different damage sources such as matrix cracking, fiber breakage during the loading [27]. This technique was used to distinguish the failure modes in laminated composite materials and there was a promising applicability of this method [28-34]. Their results presented a capable applicability of AE parameters for classification of damage mechanisms in laminated composite materials. According to their results, multivariable analysis methods like Fuzzy c-means, K-means and Genetic algorithm were found very useful for characterization of failure mechanisms in conventional laminated composite materials. However, no comprehensive study has been yet carried out regarding a multivariable analysis of $\mathrm{AE}$ signals corresponding to damage evolution in Nano-modified composites.

The purpose of this paper was to investigate the effect of PVDF nanofibrous mates on mode I energy release rate $\left(\mathrm{G}_{\mathrm{I}}\right)$ value as well as detecting the occurrence of micro cracking events. Moreover, the possibility of detecting the type of damage for the nanomodified and virgin laminates was investigated, using multivariable analysis (Fuzzy c-means) of the obtained AE signals. The mechanical data and AE parameters associated with pattern recognition analyses were used for investigation of the interlaminar properties and the relevant failure modes. The morphology of the fractured surfaces was also investigated, which had good agreement with the failure modes that were detected by AE. 


\section{Materials and specimen fabrication}

\subsection{Materials}

PVDF nanofibers were produced using electrospinning process. For the process, PVDF (Solef® 6008) provided by Solvay in the form of powder (Table 1) and Dimethyl sulfoxide and Acetone provided by Sigma Aldrich, as solvents, were used.

\subsection{Electrospinning process}

Electrospun non-woven mats were fabricated using an in-house electrospinning apparatus (Figure 1A) composed of: (1) a high voltage power supply, (2) a syringe pump (KDScientific 200 series), (3) four syringes, (4) four Teflon tubes, (5) four needles with diameter of $0.6 \mathrm{~mm}$ and (6) a grounded rotating collector $($ length $=500 \mathrm{~mm}$, diameter $=160 \mathrm{~mm}$ ) which position relative to needles can be changed. The nanofibrous mats were prepared by electrospinning $15 \%(\mathrm{w} / \mathrm{v})$ PVDF solutions in a combination of Acetone and Dimethyl sulfoxide (DMSO) (70:30 v/v). The electrospinning process was carried out at room temperature and under applied voltage of $12 \mathrm{kV}$, feed rate of $0.01 \mathrm{~mL} / \mathrm{min}$ and $120 \mathrm{~mm}$ was the distance between the collector and tip of the needle. The average fiber diameter was $500 \pm 110 \mathrm{~nm}$ (Figure1B) and the final thickness of the membrane was $45 \pm 5 \mu \mathrm{m}$ (Figure 1C).

\subsection{Specimen fabrication}

Double cantilever beam (DCB) specimens were used for mode I fracture tests. The dimensions of specimen are given by the ASTM D5528 [35] standard: width B $=20 \mathrm{~mm}$, length L = $140 \mathrm{~mm}$, 
nominal thickness $\mathrm{t}=4.2 \mathrm{~mm}$, and initial crack length $\mathrm{a}=60 \mathrm{~mm}$ (see Figure 2 ). The specimens were manufactured by stacking 14 plies of pre-impregnated woven fabric. A crack was initiated by inserting a $15 \mu \mathrm{m}$ thickness Teflon sheet in the mid-layer of the specimens; PVDF nanofibers were placed in the same interface. It's worth mentioning that for each configuration (the reference and interleaved laminates), 3 specimens were fabricated and tested.

As explained in [20], PVDF melting improves toughening and fracture behavior of laminates significantly and thus curing temperature should be higher than melt point of PVDF: $170^{\circ} \mathrm{C}$ (Table 1). Therefore, a prepreg that requires a higher curing temperature was chosen which followed a 4step cycle: a) increasing from $24{ }^{\circ} \mathrm{C}$ to $170{ }^{\circ} \mathrm{C}$ at $1{ }^{\circ} \mathrm{C} / \mathrm{min}$, b) constant temperature for $1 \mathrm{~h}$ at 170 ${ }^{\circ} \mathrm{C}$, c) increasing with $1{ }^{\circ} \mathrm{C} / \mathrm{min}$ from $170{ }^{\circ} \mathrm{C}$ to $190{ }^{\circ} \mathrm{C}$, d) constant temperature for 20 min at 190 ${ }^{\circ} \mathrm{C}$. The cooling phase is characterized by a slow constant temperature reduction at $1{ }^{\circ} \mathrm{C} / \mathrm{min}$ rate till room temperature.

\subsection{Fracture tests}

Mode I fracture tests were carried out in a computer-controlled servo-hydraulic universal testing machine Instron 8033. (Figure 2).

Since the maximum force during the DCB test was less than $100 \mathrm{~N}$, a $1 \mathrm{kN}$ load cell was inserted in the load chain to increase the precision of the results. The cross head speed was controlled at $1.5 \mathrm{~mm} / \mathrm{min}$, and the data were recorded 10 times per second.

Mode I Energy release rate for fracture testing $\left(\mathrm{G}_{\mathrm{I}}\right)$ is obtained from the beam theory (equation 1) which is presented in ASTM D5528 [32]: 


$$
G_{I}=\frac{3 P \delta}{2 B a}
$$

Where $\mathrm{P}$ is the load and $\delta$ is the displacement. As Figure 2 presents, a lens was also used to follow the crack tip and to register the crack length (a) during the test.

\subsection{AE device}

AE waveforms were recorded using an acoustic emission data acquisition system called PCI-2 and the test sampling rate was $10 \mathrm{MHz}$. A schematic definition of the recorded waveforms and their features are shown in Figure 3. The utilized AE sensor was PAC R15, which is a broadband and single-crystal piezoelectric transducer. A 2/4/6-AST preamplifier with the gain selector of the 40 $\mathrm{dB}$ was used to enhance the detected signals and the threshold was set to be $35 \mathrm{~dB}$. Before the tests, a pencil lead break procedure was used to calibrate the data acquisition system. After the calibration step, AE signals were recorded during the tests as shown in Figure 2. The AE software (AEWin) was used to extract AE signal features such as duration, rise time, amplitude, counts, energy, etc.

\section{Results and discussion}

\subsection{Mechanical and conventional AE results:}

Force-time and AE energy-time curves resulting from both virgin and nanomodified configurations are shown in Figs. 4 and 5, respectively. As presented in Figs. 4 and 5, before the propagation of delamination, there is not any considerable damage in the specimens and trend of both the modified and virgin curves is almost the same until the crack propagation. Consequently, there is not any noteworthy AE signal with high energy content. Although several weak AE peaks 
are observed which might be associated with rubbing and elastic deformations. After the elastic stage, the stored strain energy in the specimens reaches the critical value and delamination initiates. Due to the initiation of delamination, the slope of the load-time diagram decreases (Non-linearity point in ASTM5528 [36]). From Figs. 4 and 5 and after the initiation stage of delamination, there are significant $\mathrm{AE}$ events which resulted from a run-arrest extension of delamination and consequence appearance of the failure mechanisms. Two different stages are notable during the propagation of delamination: 1) the crack arresting stage, which causes the load increasing and, as a result, the stored strain energy in the specimen accumulates; 2) Propagation of delamination, which includes different kinds of failure mechanisms such as matrix cracking, fiber breakage, etc. It could be noticed by Figs. 4 and 5 that the propagation stages occur suddenly while there are some significant drops of the load after the initiation stage. Hence, the number of the AE counts rises instantaneously during the propagation stage. Since the AE signals were originated from the different failure mechanisms during the propagation stage, they provide valuable information which can be used to monitor the crack growth and arrest behaviors.

The crack length-time diagram and cumulative AE energy for the investigated specimens are illustrated in Figs. 6 and 7. It's worth mentioning that the crack growth and cumulative AE energy have a linear relationship with time and they have the same general trend.

Force-displacement and interlaminar fracture energy curves resulting from the virgin and nanomodified configurations are shown in Figure 8, respectively. As illustrated in Figure 8 and Table 2, there are some differences in the strain energy release rate for the initiation and propagation of delamination. The differences in the strain energy release rate are due to the different crack tip conditions which are explained in section 3.2. The presence of the tough melted nanofibrous mat at the opening interface enhances the strain energy that is absorbed during the 
crack propagation. Therefore, as presented in Table 1, the fracture toughness increases about $98 \%$ and $73 \%$ in the fracture initiation and propagation stages of the modified specimens, respectively. As different damage mechanisms require different levels of critical strain energy to initiate, so the increase in the strain energy release rate for the nano-modified specimens is due to different failure modes in the crack tip. The results showed that effect of the melted nanofiberous mats had more positive effect in the initiation stage of delamination. The aim of the following section is to characterize these failure mechanisms by a multivariable clustering analysis called Fuzzy C-means clustering (FCM).

\subsection{Clustering result}

FCM connected with Principal Component Analysis (PCA) were utilized to separate time to failure mechanisms based on their AE patterns. Each input AE signal is related to some classes with a degree that is called a membership grade. PCA is utilized for better visualization of the FCM outcomes. The mathematical procedures and the basic concept of these methods are well explained $[28,37]$.

In this section, important parameters of the AE signals (i.e. rise time, duration, amplitude, frequency, energy and count) are used for the PCA analysis. As can be seen from Figure 9, near $80 \%$ of the total variance of the AE signals is related to the cumulative sum of the variances of two principle components (the PCA (1) and PCA (2)).

The FCM results on the AE signals are illustrated in Figure 10 for the specimens. The results indicate three different clustered classes which are well distinguished along the first principal direction. The borders are evaluated by minimizing the squared inner-product distance using the 
simple Picard iteration method [38-40]. The percentage of the AE signals belongs to the obtained classes are summarized in Table 3.

As noted in Table 3, the percentage of the AE signals at each class varies in virgin and nano ones. The distribution of the amplitude versus rise time for each cluster is illustrated in Figure 11 and it can be observed that there is a good separation of the clusters from each other. It means that the obtained classes have specific ranges of amplitude and rise time. The orders of appearance of the AE signals in each class are illustrated in Figure 12.

As stated by previous studies [27-36] AE signal generated from each failure mode of laminated composites, such as matrix cracking, debonding and fiber breakage, has its specific ranges of amplitude and duration. Lower duration and amplitude values are related to matrix cracking, while the higher values are linked with fiber breakage. The $\mathrm{AE}$ ranges of the debonding are found to be in the middle. Consequently, by combining the results of FCM clustering and the previously mentioned results, the AE signals and failure modes could be related to each other. Therefore, it can be concluded that the AE signals of the first, second and third classes of the FCM results are related to matrix cracking, fiber-matrix debonding and fiber breakage failures, respectively.

In Figure 13 the number of the AE events in the clustered signals is compared. It can be seen that for all the clusters the total amount of the AE signals in the virgin specimen is higher than in the nanomodified specimen. Some differences are observable in the number and percentage of the classified AE events in the virgin and nanomodified specimens. From Figure 13 and Table 4, for the virgin specimen the number of the $\mathrm{AE}$ events in cluster 1, which is associated with matrix cracking, is $86 \%$ higher than the nanomodified specimen. In addition, there are significant 
differences in the number of the AE events in clusters 2 and 3 which are associated with debonding of the matrix from fiber and fiber breakage failure mechanisms, respectively.

Cumulative distribution of the AE energy is illustrated in Figure 14. The total number of the AE events released by the nanomodified interface is near one half of the total number of the AE events released by the virgin interface.

The ratio of the cumulative AE energy in the virgin specimens and nanomodified specimens versus the time of the test is plotted in Figure 15. As can be seen from Figure 15, the value of ratio varies in different stages of the loading. As a result, the effect of the melted nanomat is not the same in all the stages of the loading and the melted nanomats delay and homogenize the failure modes. The first significant crack propagation is slowed down by the presence of the nanofiber which reduced the number of the catastrophic matrix failure events. According to Figure 15, the ratio of the AE events in the initiation stage is higher than the propagation stage; this result is consistent with the results of $\mathrm{G}_{\mathrm{I}}$ values obtained during the test. It means that the nanofibers have stronger effect on the initiation stage rather than propagation. In the virgin specimens, the early propagation of delamination occurred in the resin-rich section between two adjacent plies that makes matrix cracking. In addition, it is possible for the crack tip to jump from the resin-rich section to the fibermatrix interface, which leads to debonding of the fiber from the matrix. Whereas there was a local strain hardening phenomenon in nanomodified specimens, that arrests the crack initiation. The obtained $\mathrm{AE}$ results are very helpful to understand the failure mechanisms contributed to increase the toughness of the specimens. The AE results indicate that matrix cracking damage has fewer numbers of $\mathrm{AE}$ signals in the nano-modified specimen compared with the virgin specimens. It means that the reason for the increase in the toughness of the modified specimens is not due to the thicker rich resin interface and it is mainly because of the PVDF nanofibers which were cured in 
appropriate curing temperature. The effect of the thickness increase due to the PVDF mate is in accordance with the previous works [18-19], where small increase in the toughness was observed due to inappropriate curing temperature and manufacturing condition.

For a better understanding of the toughening effect of the nanofibers, the morphology of the fractured surface for the virgin and nanomodified specimens is illustrated in Figs. 16 and 17, respectively. Fracture surface of the virgin specimen is mostly containing brittle region, this region is the crack path (the resin-rich section) near the fibers between two adjacent plies which makes matrix cracking. On the other end, fractured surface of the nanomodified specimen is a mixture of brittle and ductile regions. In the ductile region, the crack path is affected by the nanofiber interlayer and so a plastic zone occurred in front of the crack tip during the crack growth.

\section{Conclusion}

In this study, the effect of interleaved PVDF nanofibers on mode I interlaminar properties and the appeared failure modes of woven carbon/epoxy laminates was investigated. The obtained mechanical data and AE signals monitored during the DCB tests were used to investigate the effect of the nanofibers. The mechanical results proved the ability of the PVDF-nanofiberous mate to enhance $\mathrm{G}_{I}$ in the initiation and propagation of delamination. The conventional AE analysis showed the applicability of AE to detect the initiation of delamination and to follow the crack tip using the AE energy distribution and cumulative AE energy. The results showed that effect of the melted nanofiberous mats, to enhance composite delamination strength and damage tolerance, was not uniform during the test and had more positive effect in the initiation stage. In addition, multivariable analysis was applied to discriminate the failure modes and it was observed that there 
was a different percentage of failure modes in the nanomodified specimens compared with the virgin ones. Furthermore, the number of interlaminar occurred failure modes diminished in the modified composite layers. SEM pictures of the fractured surfaces illustrated that plastic deformation of the matrix and melted PVDF was the main reason for reducing the damage progression sensitivity and increasing the fracture toughness value. So it can be concluded that the nano-modification by PVDF can improve the resistance of the laminate to transversal and dynamic impact loads than can arise during woodworking.

\section{Acknowledgement}

This investigation was supported by the European Union, inside the Adriatic IPA Cross-border cooperation programme, as part of the Adria-Hub action (details in [41]).

\section{References:}

[1] Lucisano G, Stefanovic M, Fragassa C. (2016) Advances Design Solutions for High-Precision Woodworking Machines 2016. Int J Qual Res 2016; 10(1): 143-158

[2] Saghafi H, Minak G, Zucchelli A. Effect of preload on the impact response of curved composite panels, Compos Part B-Eng 2014;60:74-81.

[3] Pavlovic A, Fragassa C. Analysis of flexible barriers used as safety protection in woodworking. Int J Qual Res 2016; 10(1): 71-88

[4] Tsai GC, Chen JW. Effect of stitching on mode I strain energy release rate. Compos Struct 2005;69:1-9.

[5] Wong DWY, Lin L, McGrail PT, Peijs T, Hogg PJ. Improved fracture toughness of carbon fibre/epoxy composite laminates using dissolvable thermoplastic fibres. Compos Part A-Appl Sci Manuf 2010;41(6):759-67.

[6] Wang CH, Sidhu K, Yang T, Zhang J, Shanks R. Interlayer self-healing and toughening of carbon fiber/epoxy composites using copolymer films. Compos Part A-Appl Sci Manuf 2012;43(3):512-8.

[7] Tang G, Yan Y, Chen X, Zhang J, Xu B, Feng Z. Dynamic damage and fracture mechanism of threedimensional braided carbon fiber/epoxy resin composites. Mater Design 2001;22:21-5.

[8] Van Velthem P, Ballout W, Daoust D, Sclavons M, Cordenier F, Henry E, Dumont D, Destoop V, Pardoen T, Bailly C. Influence of thermoplastic diffusion on morphology gradient and on delamination toughness of RTMmanufactured. Compos Part A-Appl Sci Manuf 2015;72:175-83. 
[9] Sohn MS, Hu XZ, Kim JK, Walker L. Impact damage characterisation of carbon fiber/epoxy composites with multi-layer reinforcement. Compos Part B-Eng 2000;31(8):681-91.

[10] Yasaee M, Bond IP, Trask RS, Greenhalgh ES. Mode I interfacial toughening through discontinuous interleaves for damage suppression and control. Compos Part A-Appl Sci Manuf 2012;43(1):198-207.

[11] Dzenis YA, Reneker DH. United States patent 6265333: Delamination resistant composites prepared by small diameter fiber reinforcement at ply interfaces 2001.

[12] Akangah P, Lingaiah S, Shivakumar K. Effect of Nylon-66 nanofiber interleaving on impact damage resistance of epoxy/carbon fiber composite laminates. Compos Struct 2010;92(6):1432-9.

[13] De Schoenmaker B, Van der Heijden S, De Baere Ives Van Paepegem W, De Clerck K. Effect of electrospun polyamide 6 nanofibres on the mechanical properties of a glass fiber/epoxy composite. Polym Test 2013;32(8):1495-501.

[14] Palazzetti R. "Flexural behavior of carbon and glass fiber composite laminates reinforced with Nylon 6,6 electrospun nanofibers. J Compos Mater, 2015;49(27): 3407-3413.

[15] Moroni F, Palazzetti R, Zucchelli A, Pirond A. A numerical investigation on the interlaminar strength of nanomodified composite interfaces. Compos Part B-Eng, 2013;55:635-641.

[16] Alessi $\mathrm{S}$ et al. Effects of Nylon 6,6 nanofibrous mats on thermal properties and delamination behavior of high performance CFRP laminates. Polym Composite, 2015:36(7):1303-1313

[17] Saghafi H, Zucchelli A, Palazzetti R, Minak G. The effect of interleaved composite nanofibrous mats on delamination behavior of polymeric composite materials. Compos Struct 2014;109:41-7.

[18] Bovicelli F, Saghafi H, Brugo TM, Belcari J, Zucchelli A, Minak G. On Consideration the Mode I Fracture Response of CFRP Composite Interleaved by Composite Nanofibers. Procedia Mater Science 2014;3:1316-21.

[19] Magniez K, Chaffraix T, Fox B. Toughening of a carbon-fiber composite using electrospun poly(hydroxyether of bisphenol A) nanofibrous membranes through inverse phase separation and inter-domain etherification. Materials 2011;4(11):1967-84.

[20] Saghafi H, Brugo T, Minak G, Zucchelli A. The effect of PVDF nanofibers on mode-I fracture toughness of composite materials. Compos Part B-Eng 2015;72:213-6.

[21] Zhang J, Yang T, Lin T, Wang CH. Phase morphology of nanofibre interlayers: critical factor for toughening carbon/epoxy composites. Compos Sci Technol 2012;72:256-62.

[22] Magniez K, De Lavigne C, Fox BL. The effects of molecular weight and polymorphism on the fracture and thermo-mechanical properties of a carbon-fiber composite modified by electrospun poly (vinylidene fluoride) membrane. Polymer 2010;51:2585-96.

[23] Li G, Li P, Zhang C, Yu Y, Liu H, Zhang S, Jia X, Yang X, Xue Z, Ryu S. Inhomogeneous toughening of carbon fiber/epoxy composite using electrospun polysulfone nanofibrous membranes by in situ phase separation. Compos Sci Technol 2008;68:987-94.

[24] Saghafi H, Brugo T, Minak G, Zucchelli A. Improvement the impact damage resistance of composite materials by interleaving Polycaprolactone nanofibers. Engineering Solid Mechanics 2105;3:21-6.

[25] Gareth W. Beckermann, Kim L. Pickering. Mode I and Mode II interlaminar fracture toughness of composite laminates interleaved with electrospun nanofibre veils. Compos Part A-Appl Sci Manuf 2015;72:11-21.

[26] Shivakumar K, Lingaiah S, Chen H, Akangah P, Swaminathan G, Russell L. Polymer nanofabric interleaved composite laminates. AIAA J 2009;47(7):1723-9. 
[27] Barré S, Benzeggagh ML. On the use of acoustic emission to investigate damage mechanisms in glass fiber reinforced polypropylene. Compos. Sci. Tech. 1994; 52(3), 369-376.

[28] Marec A, Thomas JH, Guerjouma ER. Damage characterization of polymer-based composite materials: multivariable analysis and wavelet transform for clustering acoustic emission data. Mech. Sys. Sig. Proc. 2008; 22(6), $1441-1464$.

[29] Uenoya T. Acoustic emission analysis on interfacial fracture of laminated fabric polymer matrix composites. $J$. Acous. Emiss. 1995; 13, 95-102.

[30] de Oliveira R, Marques AT. Health monitoring of FRP using acoustic emission and artificial neural networks. Comput Struct 2008; 86: 367-373.

[31] Fotouhi M, Pashmforoush F, Ahmadi M, Refahi A. Monitoring of initiation and growth of delamination in composite materials using Acoustic Emission under quasi-static 3-point bending test. Journal of Reinforced Plastics and Composites. 2011, 30: 1481.

[32] Pashmforoush F, Fotouhi M, Ahmadi M. Acoustic emission-based damage classification of glass/polyester composites using harmony search k-means algorithm. Journal of Reinforced Plastics and Composites. 2012; 31: 671680 .

[33] Saeedifar M, Fotouhi M, Ahmadi M, Hosseini Toudeshky H. Prediction of delamination growth in laminated composites using acoustic emission and cohesive zone modeling techniques. Journal of composite structures 2015; 124: $120-127$.

[34] Fotouhi M, Ahmadi M. Acoustic Emission based study to characterize the initiation of mode I delamination in composite materials. Journal of Thermoplastic Composite Materials 2014; (19), DOI: 10.1177/0892705713519811.

[35] ASTM D5528. Standard test method for mode-I interlaminar fracture toughness of unidirectional fiber-reinforced polymer matrix composites. Annual book of ASTM standards; 2007.

[36] Huang M, Jiang L, Liaw P K, Brooks Ch R, Seeley R, Klarstrom D L. Using Acoustic Emission in Fatigue and Fracture Materials Research. Nondestructive Evaluation: Overview. 1998; 50(11).

[37] de Carvalho FAT. Fuzzy C-means clustering methods for symbolic interval data. Pattern Recognit Lett. 2007; 28: $423-437$.

[38] Fotouhi M, Heidary H, Ahmadi M, Pashmforoush F. Characterization of composite materials damage under quasi-static 3-point bending test using Wavelet and Fuzzy C-Means Clustering, Journal of Composite Materials, 2012, 46(15), 1795-1808.

[39] Fotouhi M, Teymuri C, Ahmadi M, Fracture Characteristics of AISI D2 Tool Steel Using Acoustic Emission and Fuzzy C-Means Clustering, Arabian Journal for Science and Engineering, 2013; 38 (8):2205-2217.

[40] Fotouhi M, Saeedifar M, Sadeghi SA, Ahmadi M, Minak G, Investigation of the damage mechanisms for mode I delamination growth in foam core sandwich composites using acoustic emission, Structural Health Monitoring, 2015; DOI: $10.1177 / 1475921714568403$.

[41] Savoia M, Stefanovic M, Fragassa C. Merging Technical Competences and Human Resources with the Aim at Contributing to Transform the Adriatic Area in Stable Hub for a Sustainable Technological Development. Int J Qual Res 2016; 10(1): 1-12.

\section{Table legends:}

Table 1. PVDF properties (Source: Solvay datasheet). 
Table 2. Fracture parameters obtained from mode-I fracture tests.

Table 3. Dependency percentage of the AE signals for the obtained classes.

Table 4. Relative percentage of the AE events increase in the virgin specimens compared with the nanomodified. Figure legends:

Figure 1. A) Electrospinning apparatus B) SEM micrograph of PVDF nanofibers, C) Through-thickness microscopy.

Figure 2. Sample geometry for double cantilever beam (DCB).

Figure 3. The definitions for acoustic-emission parameters [34].

Figure 4. Load-time and AE energy time curves for the reference laminate.

Figure 5. Load-time and AE energy time curves for nanomodified specimen.

Figure 6. The crack length-time diagram and cumulative AE energy for the Virgin specimen.

Figure 7. The crack length-time diagram and cumulative AE energy for the nanomodified specimen.

Figure 8. A) Force-time, B) GI-crack length curves for the non-modified and the PVDF modified specimens.

Figure 9. The percent of the total variability explained by each principal component: A) Virgin, B) Nanomdified specimens.

Figure 10. The PCA visualization of the FCM on the AE signals: A) Virgin, B) Nanomodoified specimens.

Figure11. The distributions of the Amplitude versus rise time for each cluster for the virgin and nanomodified specimens.

Figure12. The orders of the clustered AE events for the virgin and nanomodified specimens.

Figure 13. Number of AE events related to different failure mechanisms for the virgin and nanomodified specimens.

Figure 14. Cumulative distribution of the AE energy for the specimens.

Figure 15. Ratio of cumulative AE energy of virgin per nanomodified.

Figure 16. Morphology of the fractured surface for the virgin specimen and different failure mechanisms.

Figure 17. Morphology of the fractured surface for the nanomodified specimen with ductile and brittle regions and different failure mechanisms. 
Table 1. PVDF properties (Source: Solvay datasheet)

\begin{tabular}{|c|c|}
\hline Property & Value \\
\hline Form & Powder \\
\hline Specific Gravity & $1.75-1.8$ \\
\hline Glass Transition Temperature $\left({ }^{\circ} \mathrm{C}\right)$ & -40 \\
\hline Vicat softening Temperature $\left({ }^{\circ} \mathrm{C}\right)$ & $135-145$ \\
\hline Melting Temperature $\left({ }^{\circ} \mathrm{C}\right)$ & $170-175$ \\
\hline
\end{tabular}

Table 2. Fracture parameters obtained from mode-I fracture tests

\begin{tabular}{|c|c|c|c|c|c|c|c|c|}
\hline & \multicolumn{2}{|c|}{$\begin{array}{c}G_{I}-\text { Initiation } \\
(\mathrm{N} / \mathrm{m})\end{array}$} & \multicolumn{2}{|c|}{$\begin{array}{c}G_{I}- \\
\text { Propagation } \\
(\mathrm{N} / \mathrm{m})\end{array}$} & \multicolumn{2}{|c|}{$\begin{array}{c}\text { Maximum } G_{I} \\
(\mathrm{~N} / \mathrm{m})\end{array}$} & \multicolumn{2}{|c|}{$\begin{array}{c}\text { Maximum Force } \\
(\mathrm{N})\end{array}$} \\
\cline { 2 - 9 } & Mean & S.D. & Mean & S.D. & Mean & S.D. & Mean & S.D. \\
\hline $\begin{array}{c}\text { Reference } \\
\text { Laminates }\end{array}$ & 254 & 5 & 307 & 17 & 349 & 24 & 32.2 & 2.0 \\
\hline $\begin{array}{c}\text { PVDF-modified } \\
\text { Laminates }\end{array}$ & 503 & 26 & 532 & 97 & 637 & 141 & 43.72 & 2.11 \\
\hline Variation (\%) & \multicolumn{2}{|c|}{+98} & \multicolumn{2}{|c|}{+73.3} & \multicolumn{2}{|c|}{+82.5} & \multicolumn{2}{|c|}{+35.7} \\
\hline
\end{tabular}


Table 3. Dependency percentage of the AE signals for the obtained classes.

\begin{tabular}{|l|l|l|l|}
\hline Name & $\begin{array}{l}\text { Dependency } \\
\text { percentage on } \\
\text { the first class }\end{array}$ & $\begin{array}{l}\text { Dependency } \\
\text { percentage on the } \\
\text { second class }\end{array}$ & $\begin{array}{l}\text { Dependency } \\
\text { percentage on } \\
\text { the third class }\end{array}$ \\
\hline Virgin & 39.20 & 33.82 & 26.98 \\
\hline Nanomodified & 35.81 & 36.7 & 27.5 \\
\hline
\end{tabular}

Table 4. Relative percentage of the AE events increase in the virgin specimens compared with the nanomodified.

\begin{tabular}{|c|c|c|c|}
\hline $\begin{array}{c}\text { (AE events of virgin-AE events } \\
\text { of Nano)/AE events of AE) }\end{array}$ & Matrix cracking & Debonding & Fiber breakage \\
\hline Percentage $(\%)$ & 86 & 56 & 67 \\
\hline
\end{tabular}



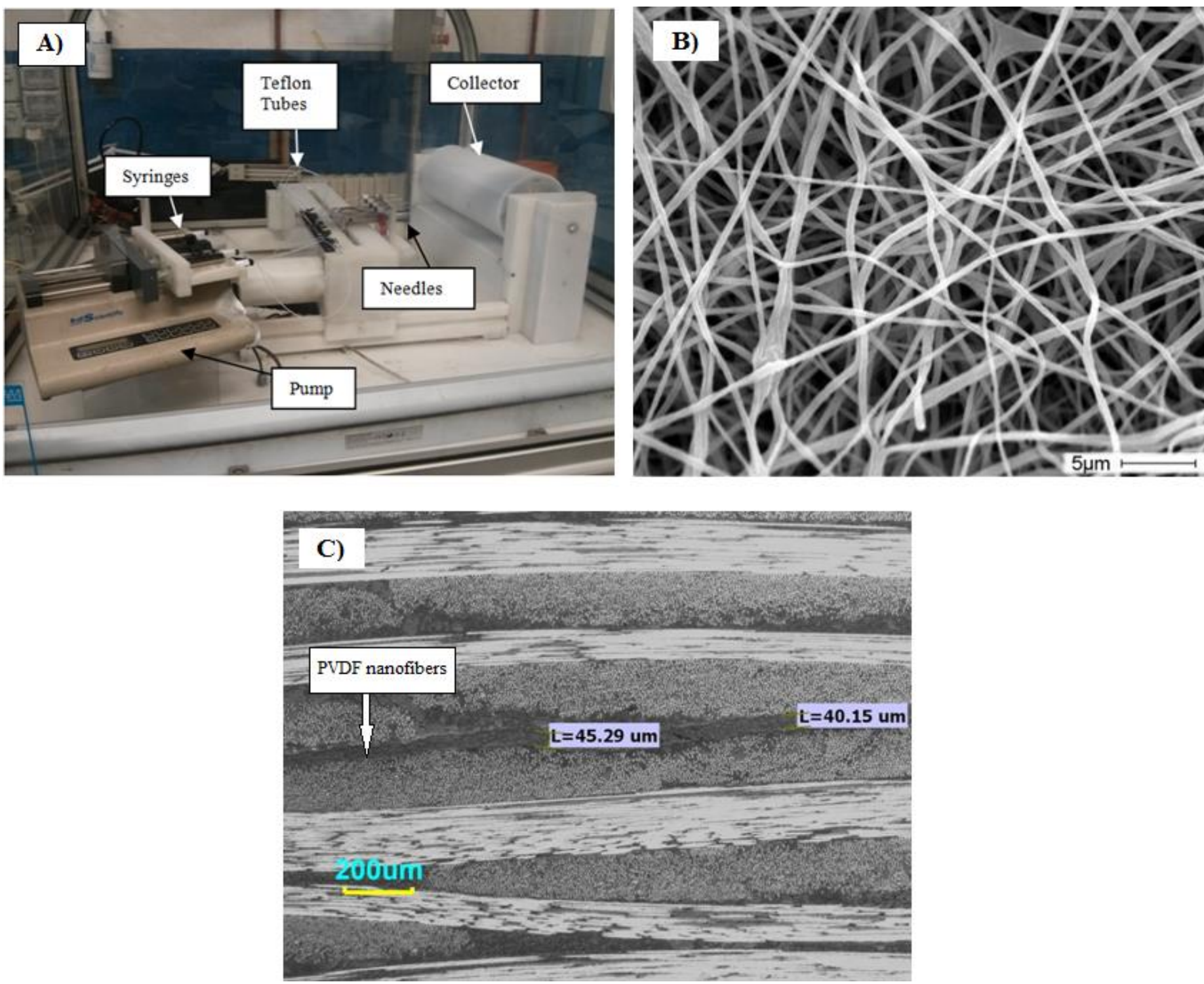

Figure 1. a) Electrospinning apparatus b) SEM micrograph of PVDF nanofibers c) Through-thickness microscopy. 

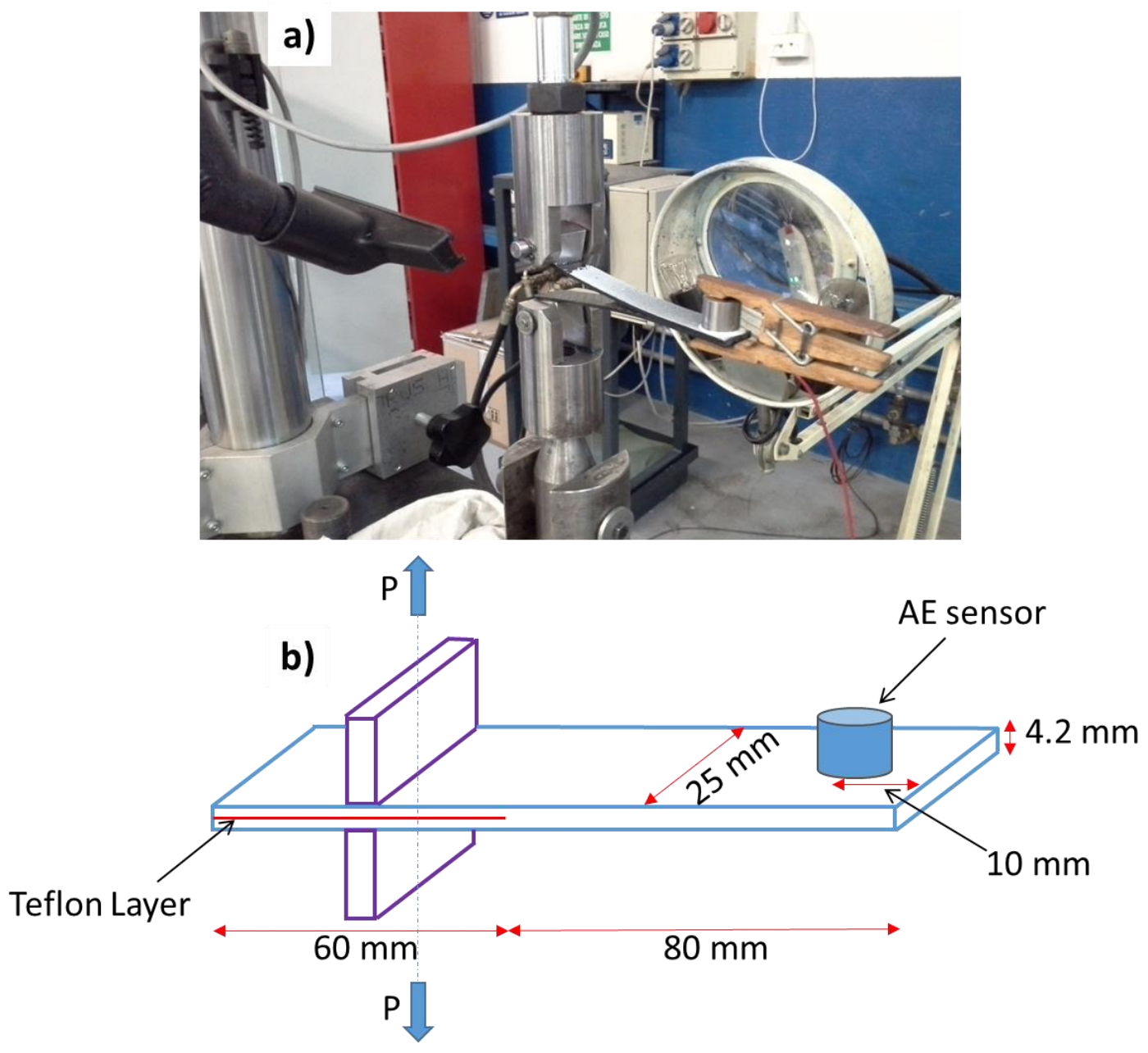

Figure 2. a) A view of experimental procedure and b) a scheme, for the tests. 


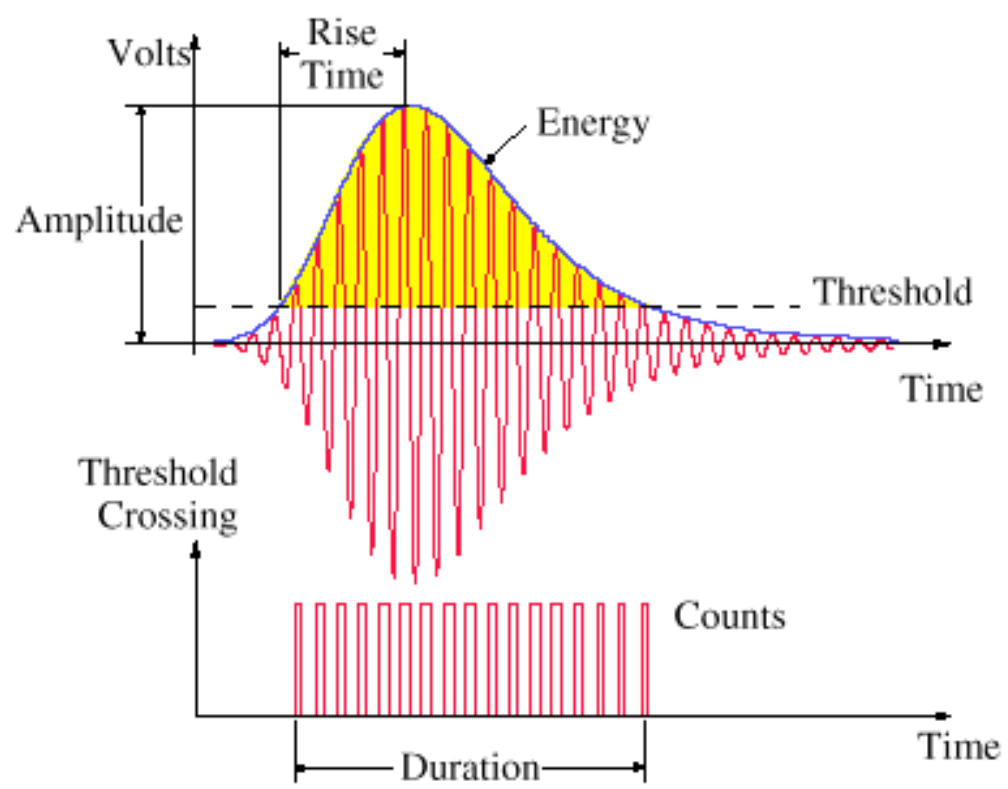

Figure 3. The definitions for acoustic-emission parameters [34].

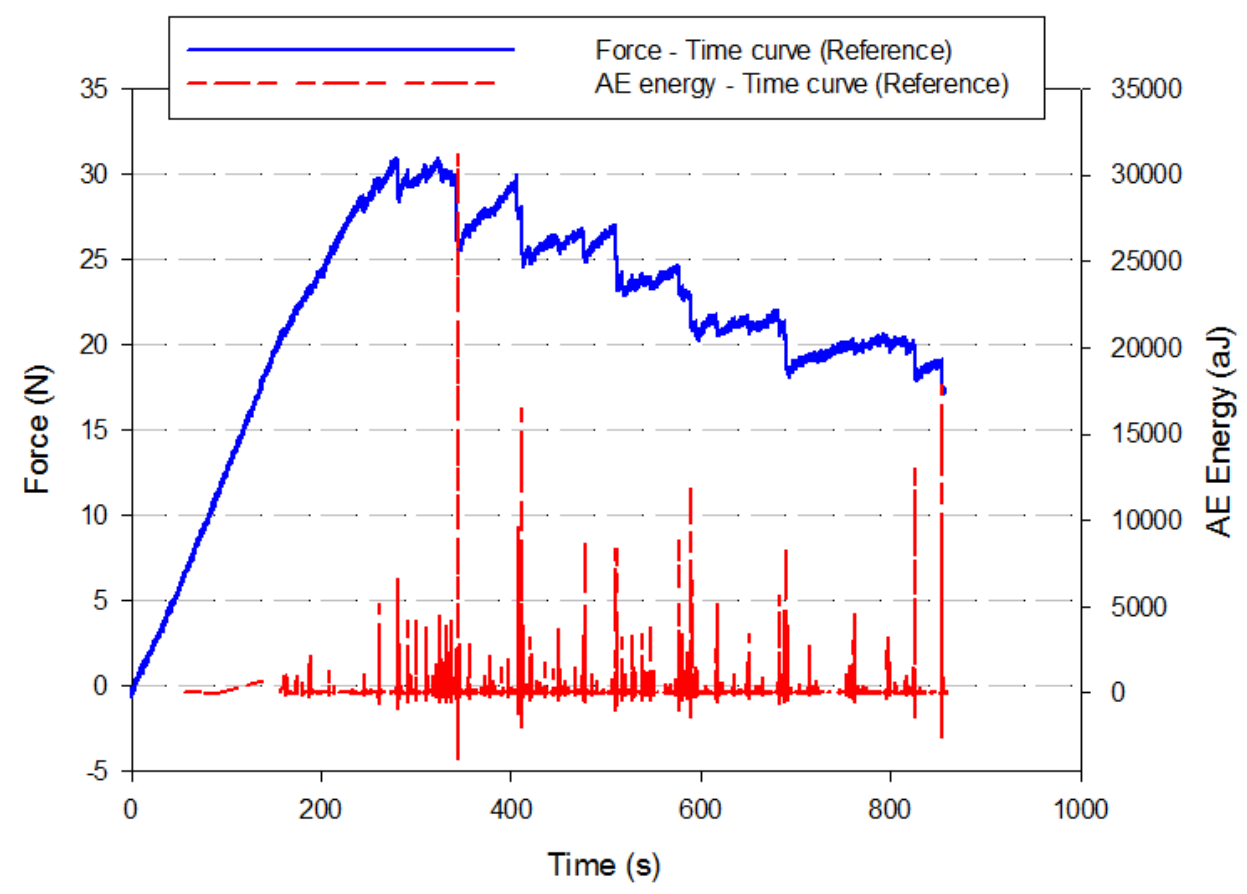

Figure 4. Load-time and AE energy time curves for the reference laminate. 


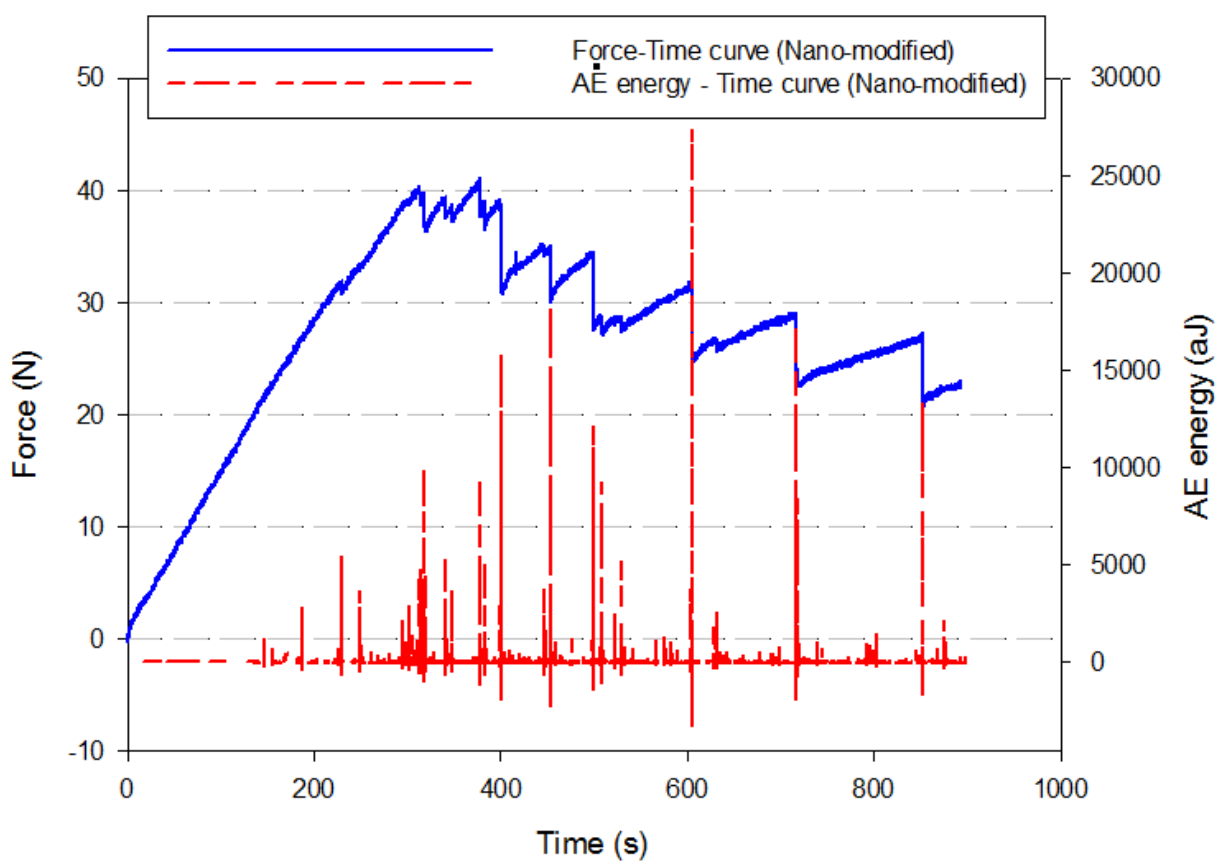

Figure 5. Load-time and AE energy time curves for nanomodified specimen. 


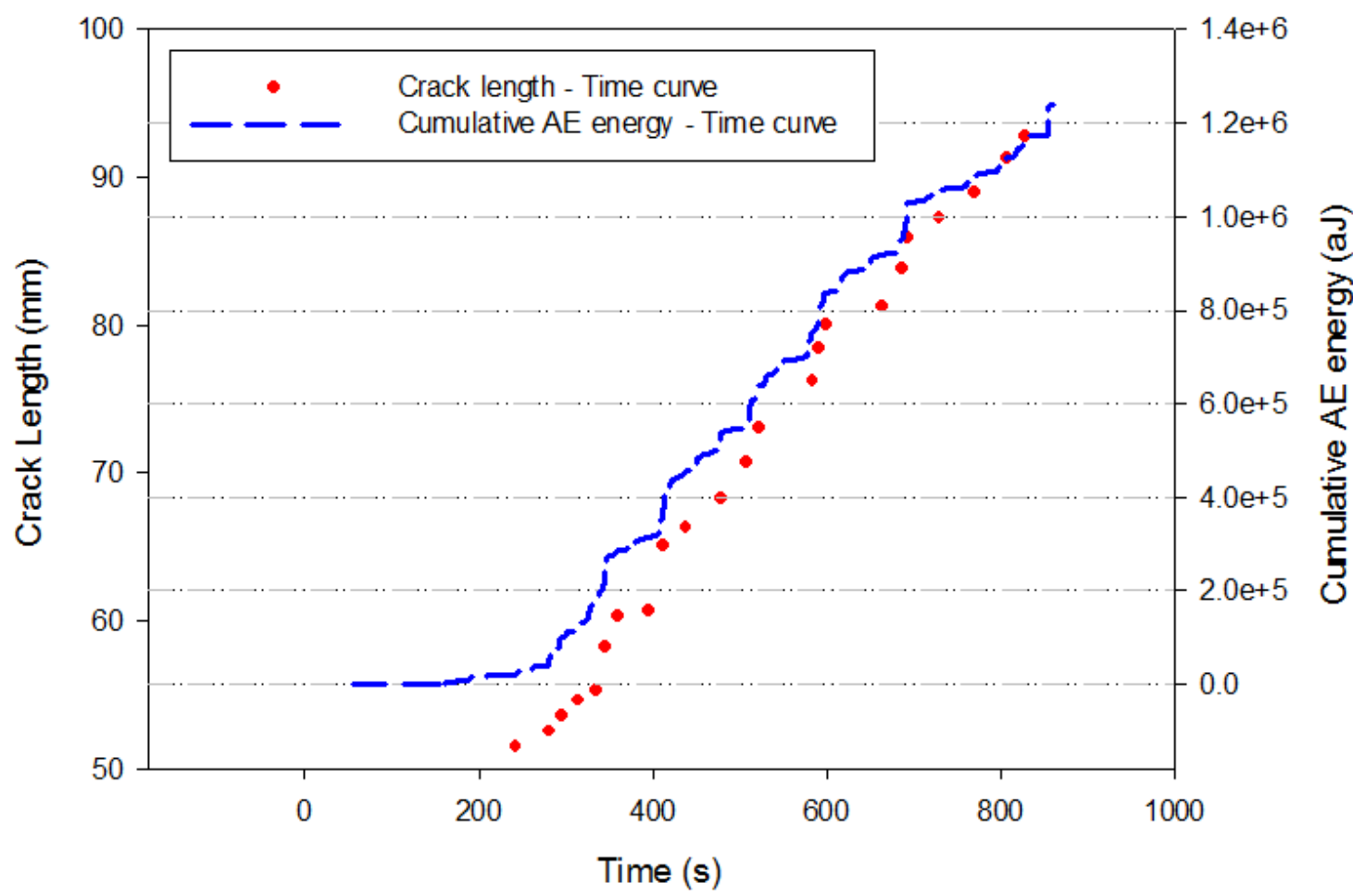

Figure 6. The crack length-time diagram and cumulative AE energy for the Virgin specimen. 


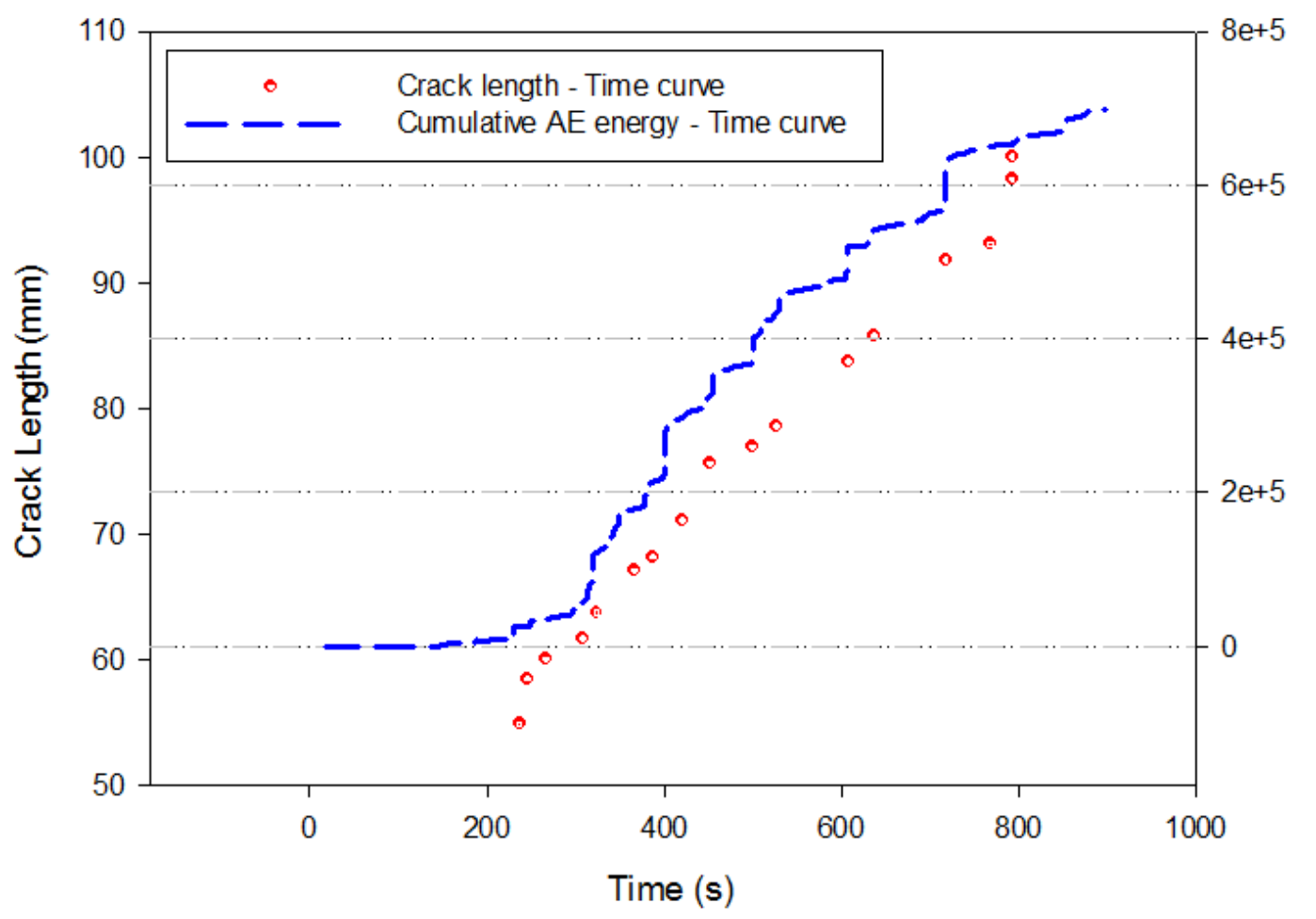

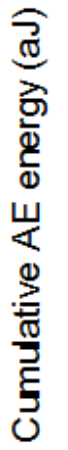

Figure 7. The crack length-time diagram and cumulative AE energy for the nanomodified specimen. 

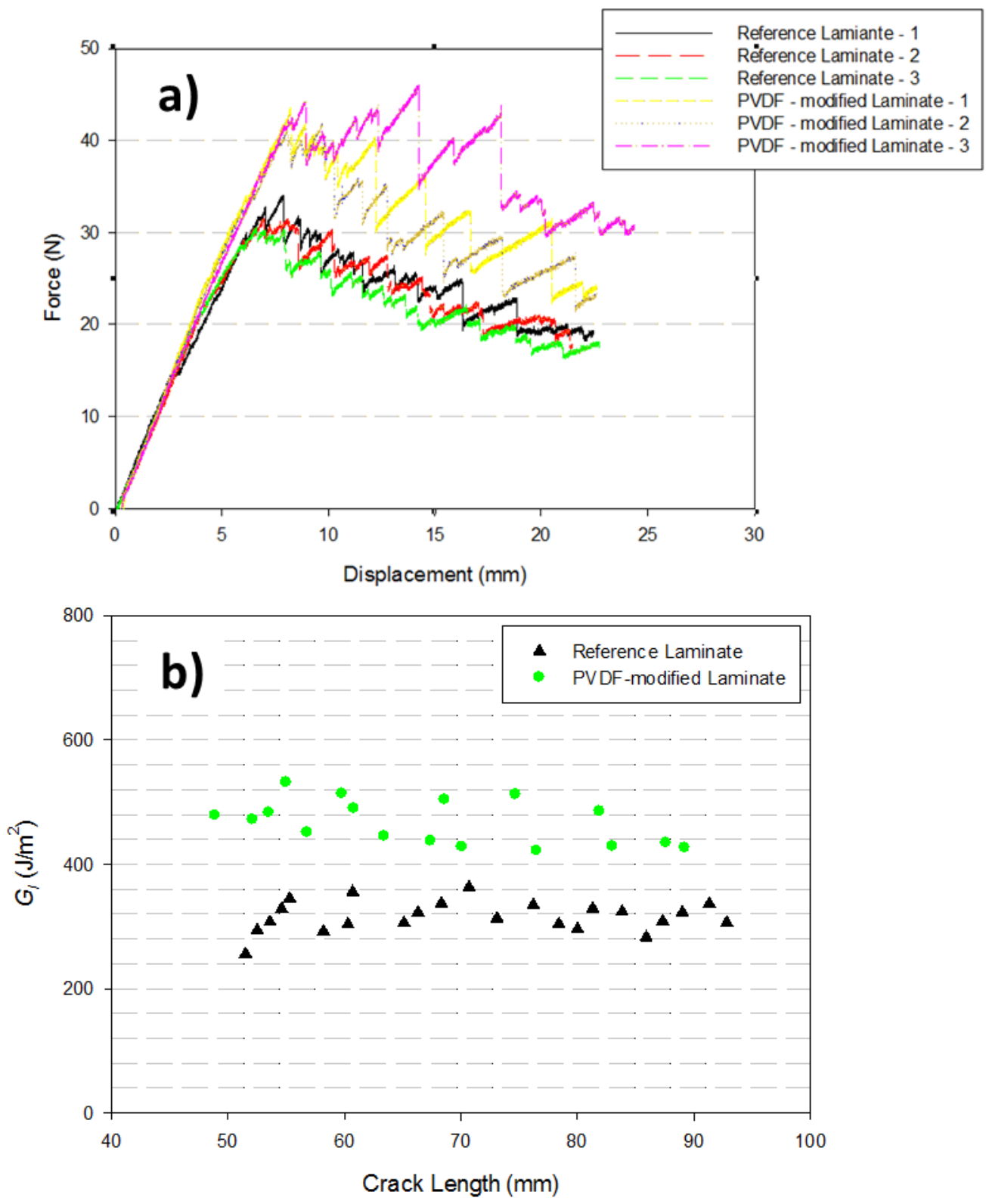

Figure 8. a) Force-time, b) GI-crack length curves for the non-modified and the PVDF modified specimens. 

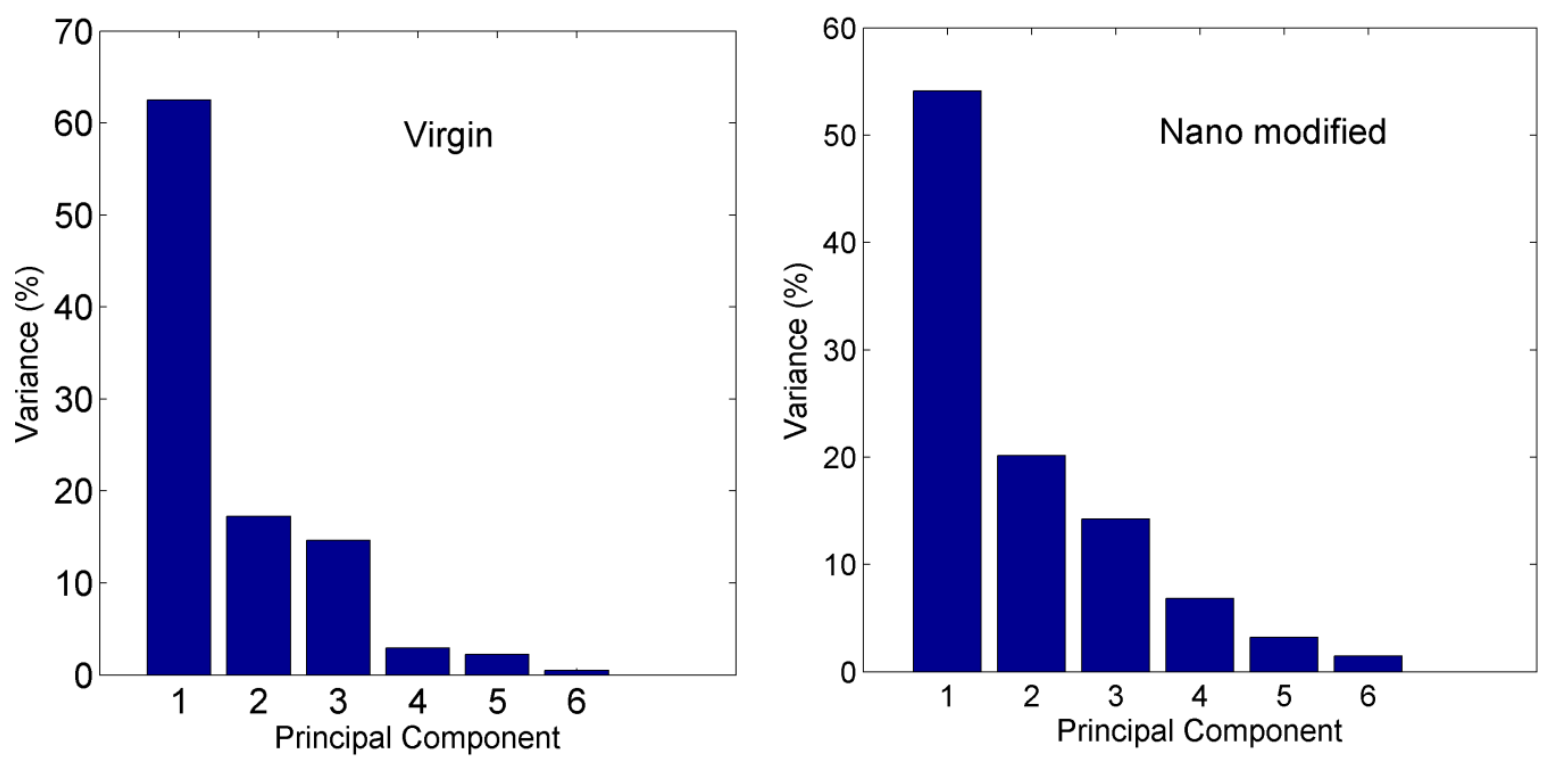

Figure 9. The percent of the total variability explained by each principal component for the virgin and nanomdified specimens.
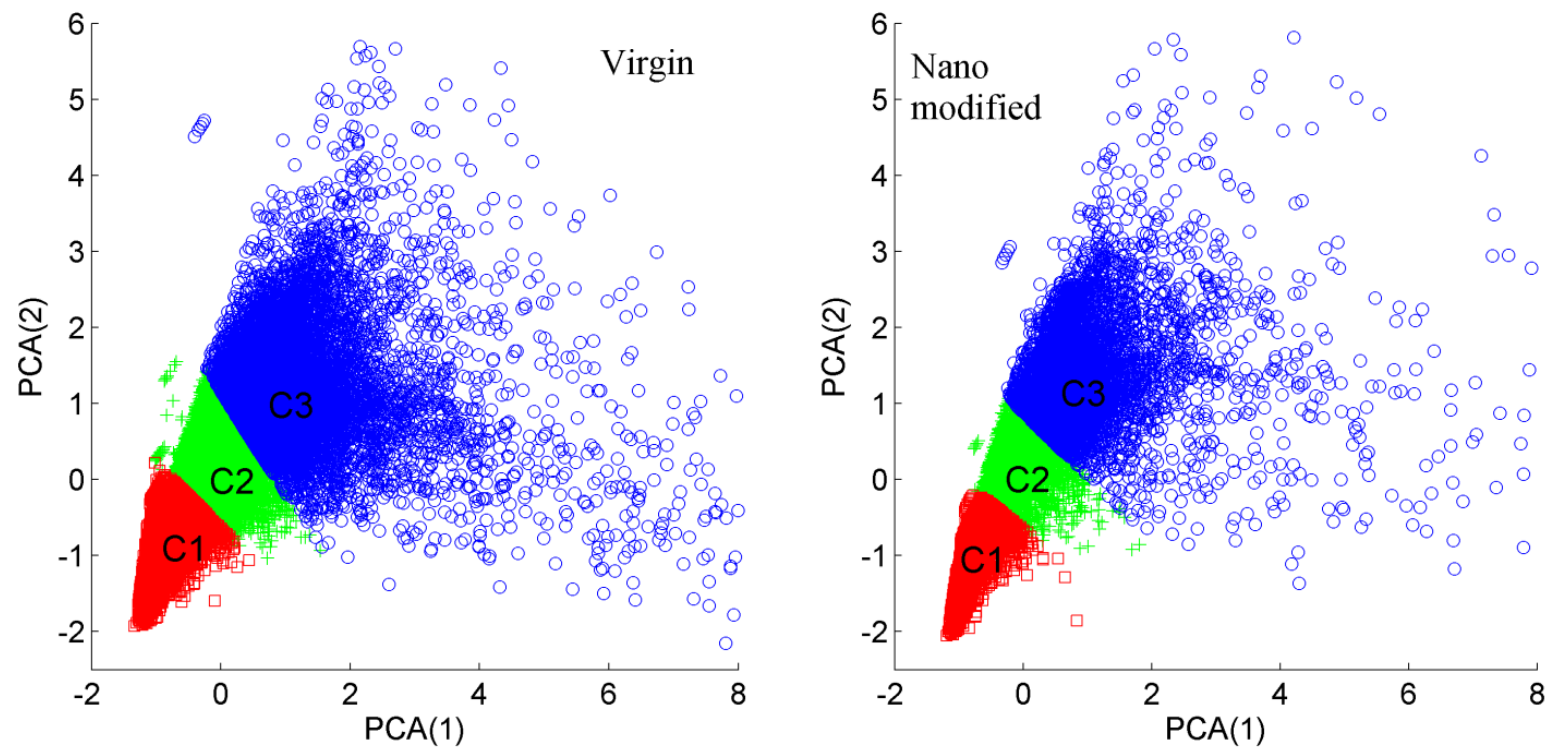

Figure 10. The PCA visualization of the FCM on the AE signals for the virgin and nanomodoified specimens 

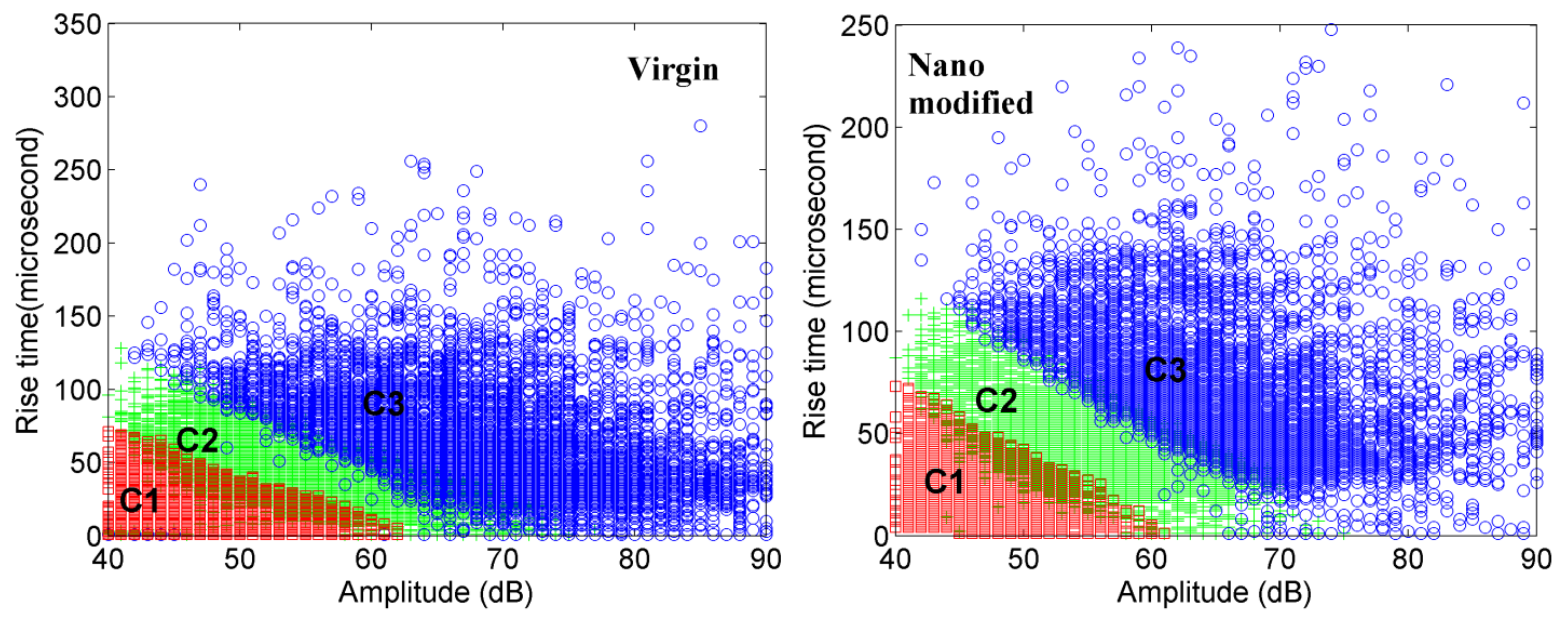

Figure11. The distributions of the Amplitude versus rise time for each cluster for the virgin and nanomodified specimens.
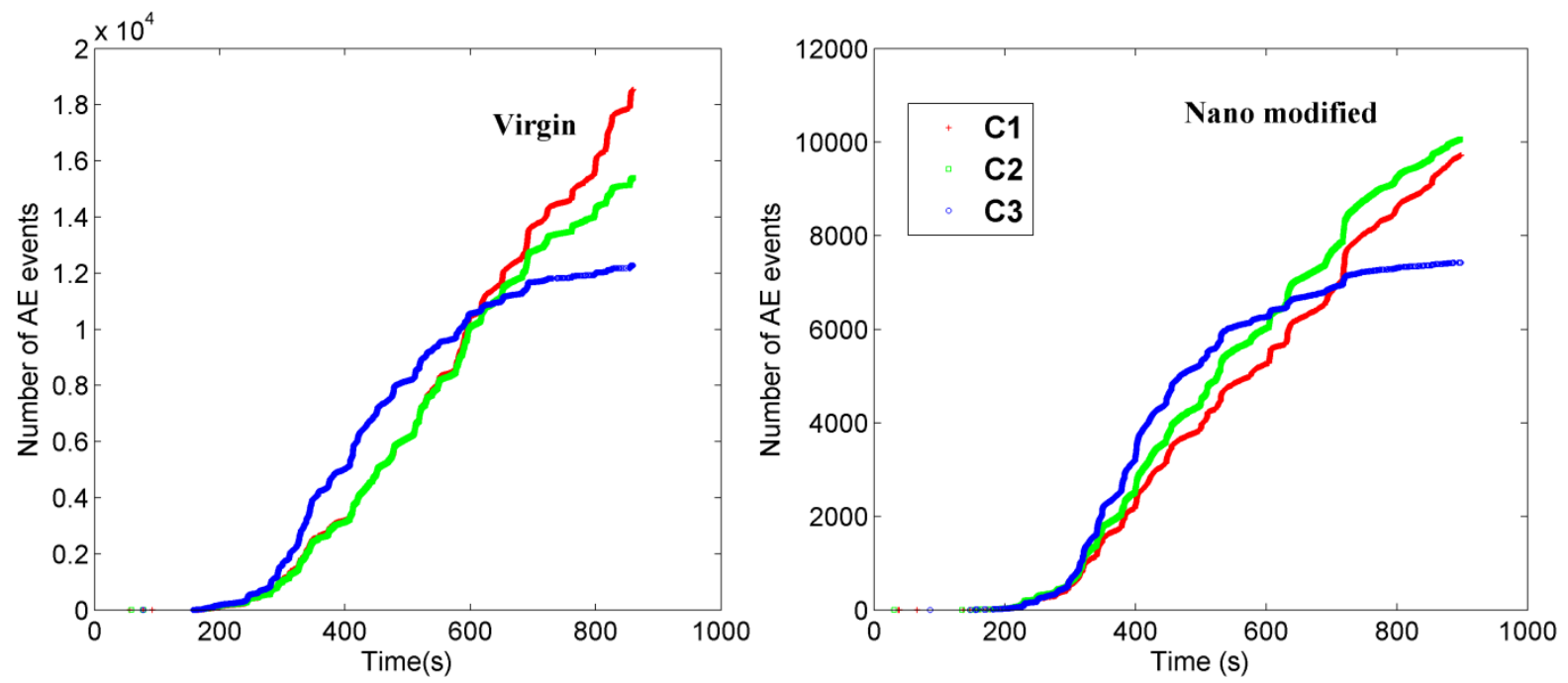

Figure12. The orders of the clustered AE events for the virgin and nanomodified specimens. 


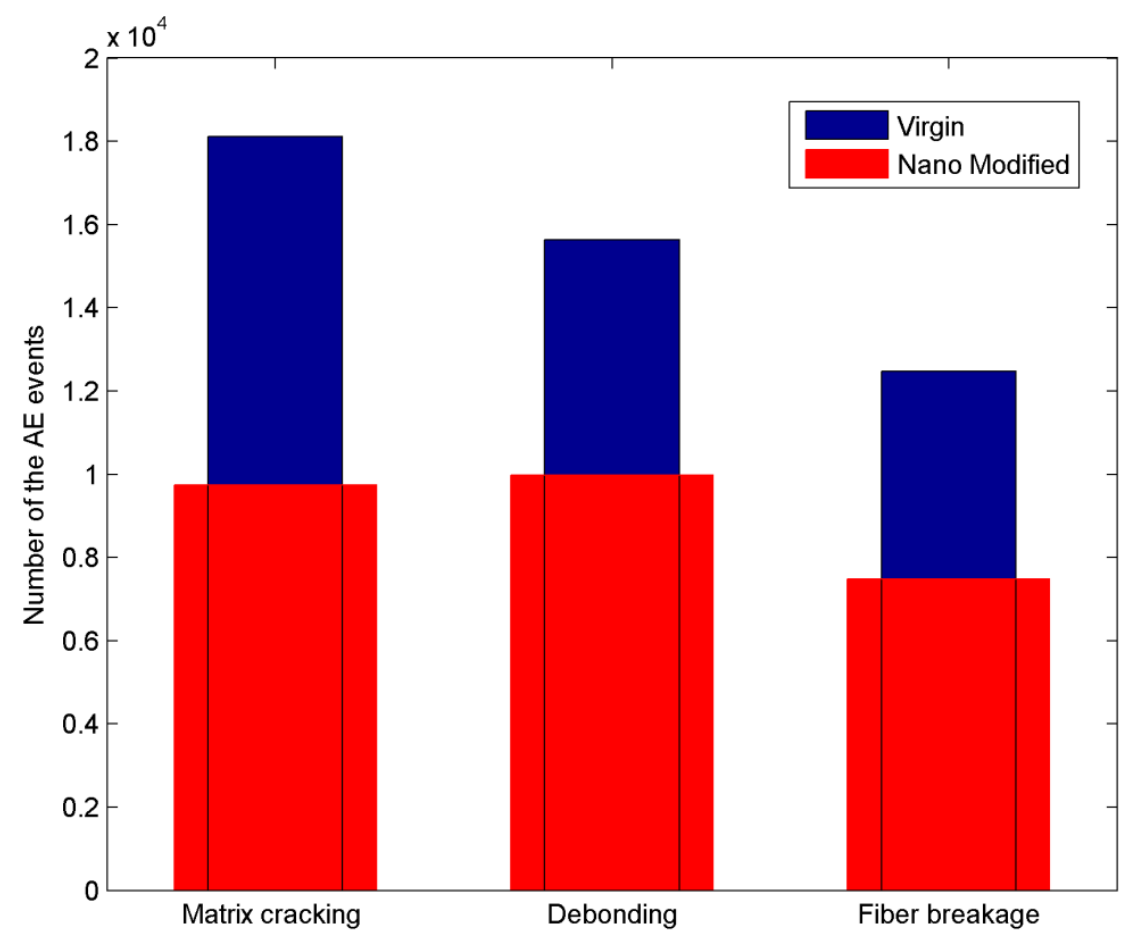

Figure 13. Number of AE events related to different failure mechanisms for the virgin and nanomodified specimens 


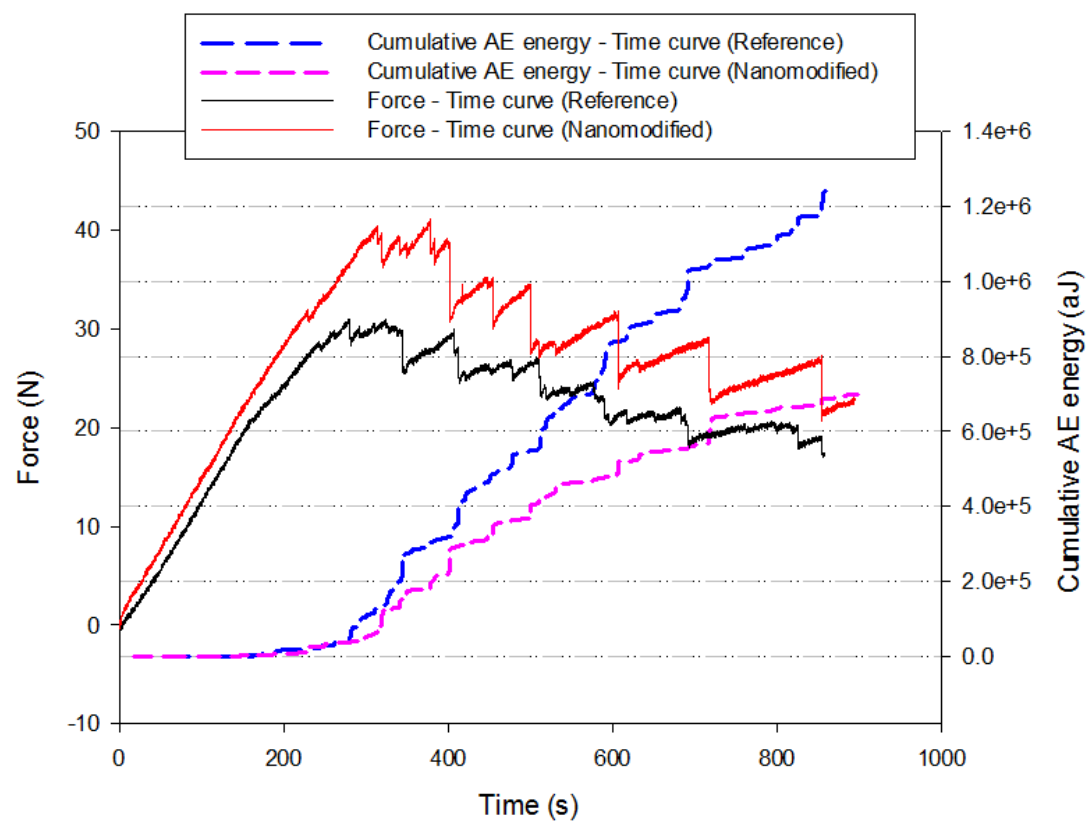

Figure 14. Cumulative distribution of the AE energy for the specimens

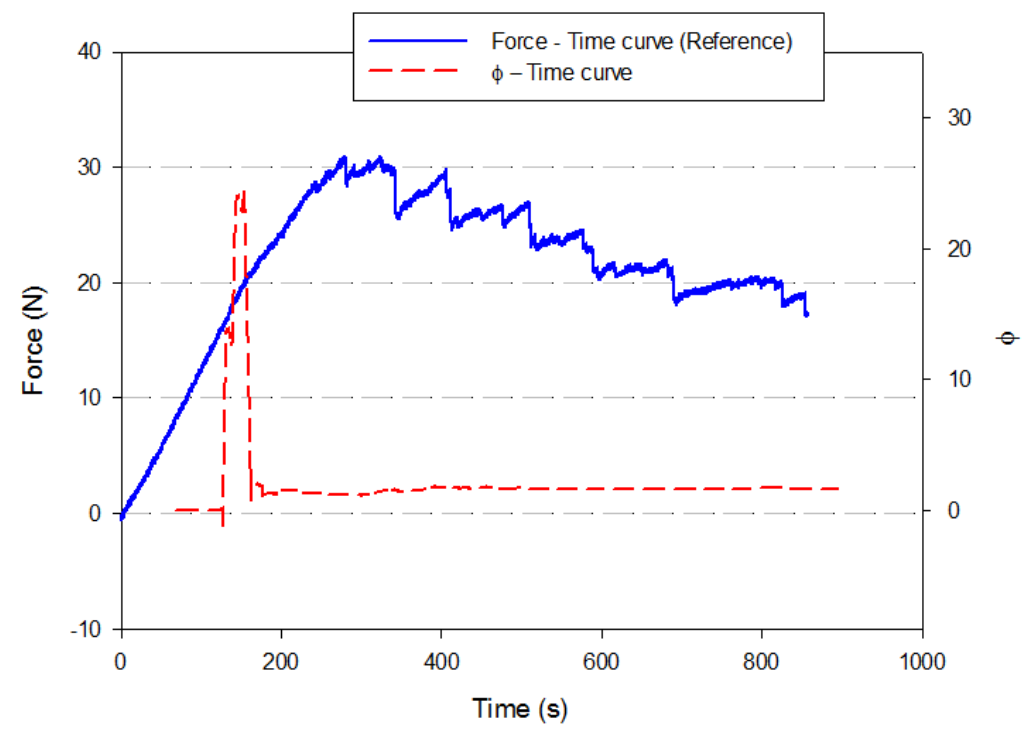

Figure 15. Ratio of cumulative AE energy of virgin per nanomodified. 


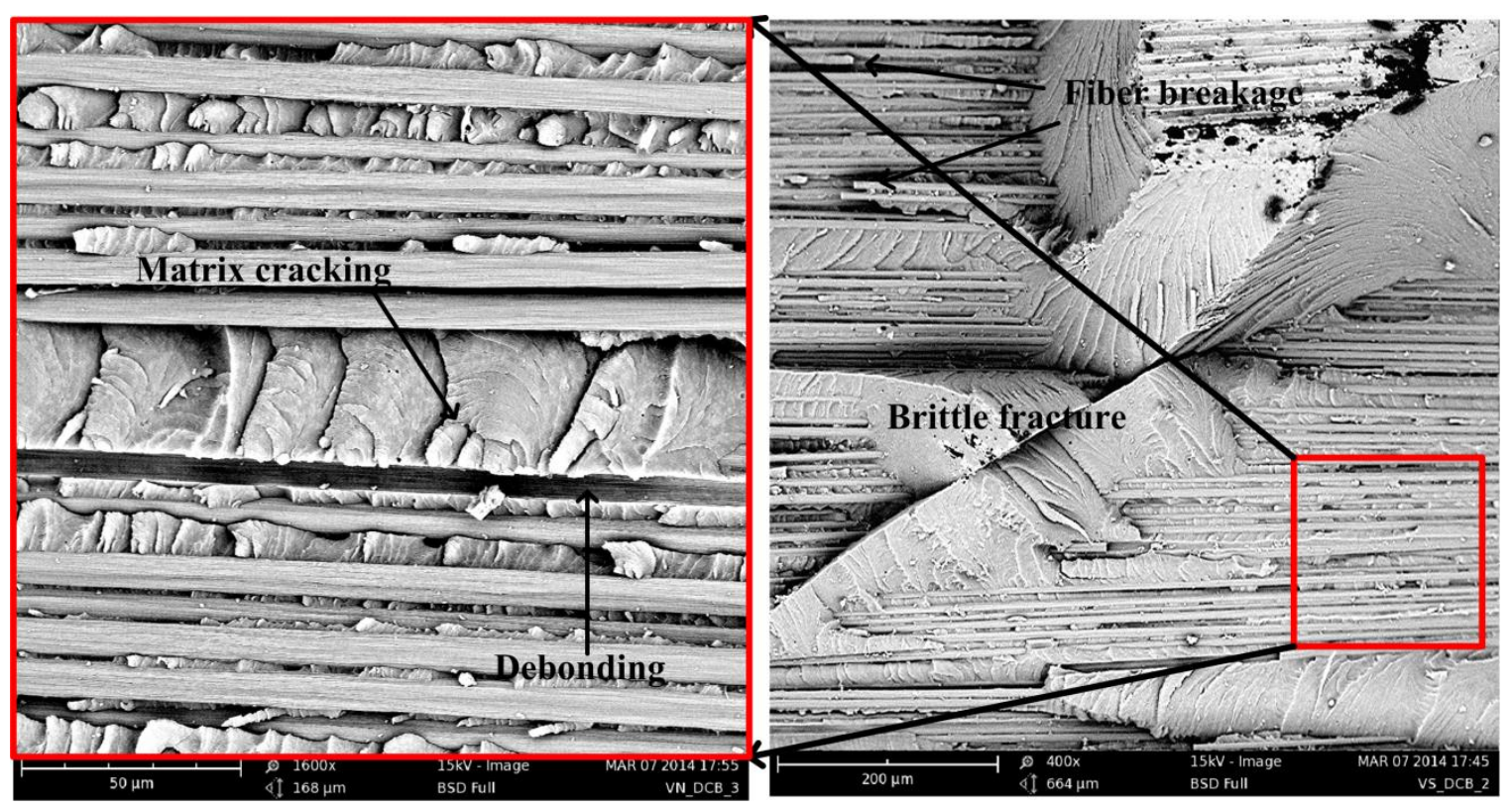

Figure 16. Morphology of the fractured surface for the virgin specimen and different failure mechanisms.

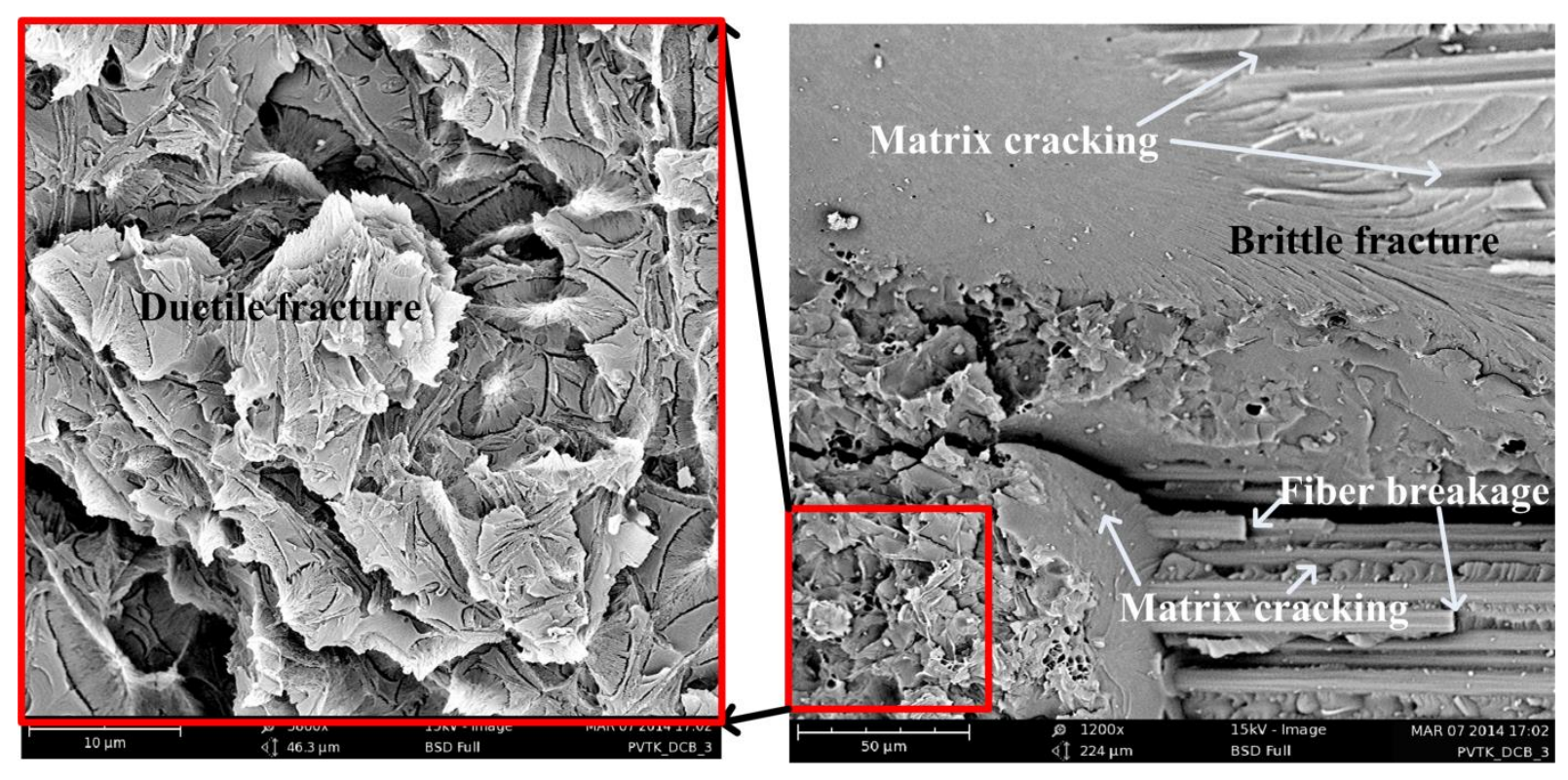

Figure 17. Morphology of the fractured surface for the nanomodified specimen with ductile and brittle regions and different failure mechanisms. 